Brit. Heart F., 1967, 29, 289.

\title{
Pulmonary Artery Banding for Ventricular Septal Defect
}

\author{
R. G. GRAINGER, R. E. NAGLE, C. PAWIDAPHA, D. S. ROBERTSON, D. G. TAYLOR, \\ J. A. THORNTON, D. VEREL, AND R. B. ZACHARY \\ From the Cardiovascular Unit, City General Hospital, and the Children's Hospital, Sheffield
}

It is well known that there is a very high mortality in children with ventricular septal defect, who develop heart failure in early infancy (Marquis, 1950; Boesen and Vendel, 1955). Morgan, Griffiths, and Blumenthal (1960) reviewed 125 children up to 14 years of age with ventricular septal defect. Of these, 17 developed heart failure in the first six months of life, 10 dying before their first birthday. None of the remaining 115 children died from their cardiac disease during the period of observation. Lynfield et al. (1961) reported serial catheter studies on children with ventricular septal defect. They found that if symptoms were present in the first year of life, the prognosis was bad, and they demonstrated that some of these children developed a progressive increase in pulmonary vascular resistance and an increasing pulmonary artery pressure. Kaplan et al. (1963) confirmed these findings.

In an attempt to reduce the high mortality of ventricular septal defect causing heart failure in infancy, Muller and Dammann (1952) employed surgical constriction of the main pulmonary artery. The objectives were to reduce the high blood flow to the lungs, and to protect the pulmonary vasculature from the high pulmonary artery pressure which might develop in the untreated children. Muller and Dammann based their treatment upon previous experimental work in which a band or tape had been used to constrict the pulmonary artery in dogs (Reid, 1924; Holman and Beck, 1926; Gerbode and Selzer, 1948). They initially produced the constriction by excising a segment of artery (Hufnagel, Roe, and Barger, 1951). Their later experience with the technique demonstrated the value of the operation in infants aged from 5 weeks to 2 years. Pulmonary hyperæmia due to left-to-right shunts was alleviated

Received March 31, 1966. in 36 operations which were performed with a mortality of 33 per cent (Thompson, Muller, and Dammann, 1958; Dammann et al., 1961). The range of the operation was extended to children with lesions not suitable for corrective surgery (single ventricle, septum primum, interruption of the aortic arch), and to older children who were developing progressive vascular disease.

Similarly encouraging results were reported by Fowler et al. (1958) and Albert et al. (1961). These latter workers used a simple band of umbilical tape, basing this technique on experimental work on dogs (Albert, Atik, and Fowler, 1958). Confirmation of these satisfactory reports has come from Therkelsen, Gammelgaard, and Boesen (1959), Smith and MacEachen (1960), Morrow and Braunwald (1961), Willman et al. (1962), Ochsner et al. (1962), Craig and Sirak (1963), and Goldblatt et al. (1965).

Reports of subsequent operations to repair the ventricular septal defect and restore the lumen of the pulmonary artery have been far less frequent. Sirak, Hosier, and Clatworthy (1959) report the case of a 3-month-old infant in whom the pulmonary artery was narrowed by a tuck in 1955 . When recatheterized at the age of 28 months he had cyanosis and clubbing with a normal pulmonary artery pressure beyond the constriction and a right-to-left shunt through a ventricular septal defect. Successful corrective surgery was performed in this child and on a single case reported by Mills et al. (1960). Dammann et al. (1961) re-operated on 11 cases with 4 deaths. In one, the pulmonary artery was reconstricted when an inoperable lesion was found. However, in three cases satisfactory post-operative pressures were measured in the pulmonary artery, and in two others the results were considered to be 289 good. 
In this paper we report our experiences of the past six years during which we have adopted the method of banding the pulmonary artery in infants with uncontrollable heart failure caused by septal defects.

\section{THE CHILDREN}

The series consists of 60 children under the age of 3 years who were selected from some 500 referred to us by the pædiatricians of the Sheffield region, between January 1960 and September 1964.

Owing to our previous experience of the high mortality in infants under the age of 3 years presenting in heart failure, and the occasional development of Eisenmenger's reaction terminating fatally under the age of 10 years, it became our mutually agreed policy to investigate thoroughly those infants whose clinical condition suggested they were at risk. The majority of the 60 children included in this survey were suffering from uncontrollable cardiac failure, and from failure to thrive.

\section{Diagnostic Methods}

The techniques of cardiac catheterization and of selective bi-plane Schonander angiocardiography have been fully described by Grainger, Taylor, and Verel (1966). Briefly, the diagnosis of a left-to-right shunt was best established by a left atrial injection of contrast medium, but right ventricular and pulmonary artery injections also proved very valuable if the left atrium could not be entered. The hæmodynamic state of the pulmonary circulation was assessed from the oximetry and measurement of intracardiac pressure. In this series aortography was rarely performed.

In 59 of these 60 infants, a left-to-right shunt was correctly diagnosed by our catheterization technique. Our diagnostic procedure does not generally permit a firm diagnosis of a patent ductus, unless traversed by the catheter, if there is another proximal defect transmitting a left-to-right shunt. This is discussed later, and appreciation of this fact influences the surgical technique.

In an attempt to reduce the pulmonary blood flow and its dangerous sequelæ, 48 of these children had their pulmonary artery banded.

\section{Indications for PUlmonary Artery Banding}

The indications for pulmonary artery banding were primarily clinical and consisted essentially of pulmonary hyperæmia with uncontrollable heart failure. The infants presented a fairly constant clinical picture, with tachycardia, tachypnœea, and dyspnœa. The majority had a history of repeated respiratory infection, but most of these episodes were probably due to pulmonary congestion and odema. Many of the children could not suck or feed adequately. All children had an enlarged heart, and many had hepatomegaly and severe congestive failure which had failed to respond to medical treatment.

None of the children operated upon had reached average weight for age and sex, and the considerable majority were neither gaining weight nor thriving.

\section{SURgical Technique}

The first three operations were performed by $\mathrm{Mr}$. R. B. Zachary and the remainder by Mr. D. G. Taylor. The chest was opened by a left antero-lateral thoractomy through the fourth rib interspace. The incision was extensive enough to permit careful inspection of the aortic arch for the presence of a patent ductus. This is an essential part of the operation, as our catheter investigation technique may fail to demonstrate a patent ductus in the presence of a more proximal left-to-right shunt.

If a patent ductus was present, it was ligated or divided. The pulmonary arterial and aortic pressure were then measured by needle puncture. A silk cord, or more recently, a nylon tape was then threaded round the main pulmonary artery and gradually tightened until the pressure beyond the ligature was reduced to within normal limits. As a general guide, a reduction of pulmonary arterial pressure to at least 50 per cent of its previous level was achieved with significant reduction in the amplitude of pulmonary artery oscillations.

\section{RESULTS}

In order to illustrate the natural history of the type of cardiac defect from which these infants suffered, those children who were not operated upon will be discussed first.

The Unoperated Group. Of the 60 children reviewed here, 12 were not operated upon. Two of them were found at the catheterization study to have only a slight left-to-right shunt (under 1.5:1) and to have normal right ventricular pressure. This suggested that the indication for catheterization (failure to thrive) was not primarily of cardiac origin. Operation was not advised and both children are alive and well, four years and two years later.

One infant was diagnosed as having a small ventricular septal defect and immediate surgery was not recommended. The child left the country, and on return three years later, no cardiac murmur was heard. Presumably the defect had closed spontaneously. One child of $2 \frac{1}{2}$ years was found on catheterization to have already developed an Eisenmenger reaction, with reversal of shunt. The child, who had permanent cyanosis with moderate clubbing, was considered inoperable.

In one child the right ventricular pressure was $80 / 0 \mathrm{~mm} . \mathrm{Hg}$ and the outflow tract pressure was $40 / 0 \mathrm{~mm}$. Hg. This was considered to be an acquired pulmonary outflow obstruction likely to protect the lungs from the effects of the left-to-right shunt. Her tachypnœa subsided with medical treatment. She has grown normally and is now aged 5 years and is free of symptoms. The cardiac signs persist, but she has no cyanosis.

Three of these 12 children were in fact operated upon but it appeared at operation that the major 
left-to-right shunt was through a patent ductus. In each case, the pulmonary artery pressure fell to normal after ligation of the ductus, and pulmonary artery banding was therefore not performed. Four of the 12 were recommended for banding of the pulmonary artery but for various reasons the operation was postponed. All four children died from their cardiac lesion within three weeks of investigation before the postponed surgery could be undertaken.

The Operated Group. Banding of the pulmonary artery was done in 48 of the 60 children. The diagnoses of these 48 children are presented in Table $I$, in which it will be seen that 29 are still alive. The results of pulmonary artery banding in solitary ventricular septal defect, and in this lesion combined with other abnormalities, are more readily appreciated from this table than by description.

An erroneous pre-operative diagnosis was made in one child who did not survive operation. This child is included in the operated group illustrated in Fig. 1 (Case 5).

Mortality. The age at operation and the outcome are illustrated in Fig. 1. It is seen that there is a
TABLE I

DIAGNOSIS IN OPERATED CASES

\begin{tabular}{|c|c|c|c|}
\hline \multirow[t]{2}{*}{ Diagnosis } & \multirow[t]{2}{*}{ Alive } & \multicolumn{2}{|c|}{ Deadt } \\
\hline & & Early & Late \\
\hline $\begin{array}{l}\text { Ventricular septal defect } \\
\text { Ventricular septal defect } \\
\text { and patent ductus } \\
\text { Ventricular septal defect } \\
\text { + atrial septal defect } \pm \\
\text { patent ductus } \\
\text { Ventricular septal defect } \\
\text { + patent ductus + co- } \\
\text { arctation } \\
\begin{array}{ll}\text { Atrial septal defect } & \ldots \\
\text { Misdiagnosis } & \ldots\end{array}\end{array}$ & $\begin{array}{l}10 \\
16\left(D^{*}-9\right) \\
2 \\
1\end{array}$ & $\begin{array}{l}3 \\
2 \\
2\end{array}$ & $\begin{array}{l}3 \\
2\end{array}$ \\
\hline . $\quad \ldots$ & 29 & 11 & 8 \\
\hline
\end{tabular}

$\star D=$ Duct traversed by cardiac catheter.

† Early death =death within three weeks of operation.

high mortality in infants operated upon under the age of 6 weeks. This age-group accounts for more than half the total mortality in the whole series of 48 bandings, only 5 out of 15 surviving. These figures suggest that it would have been reasonable to defer operation in these small infants until they were older. However, their condition was desperate and deteriorating. The most frequent cause of death in this group was cardiac arrest, either during operation or in the succeeding

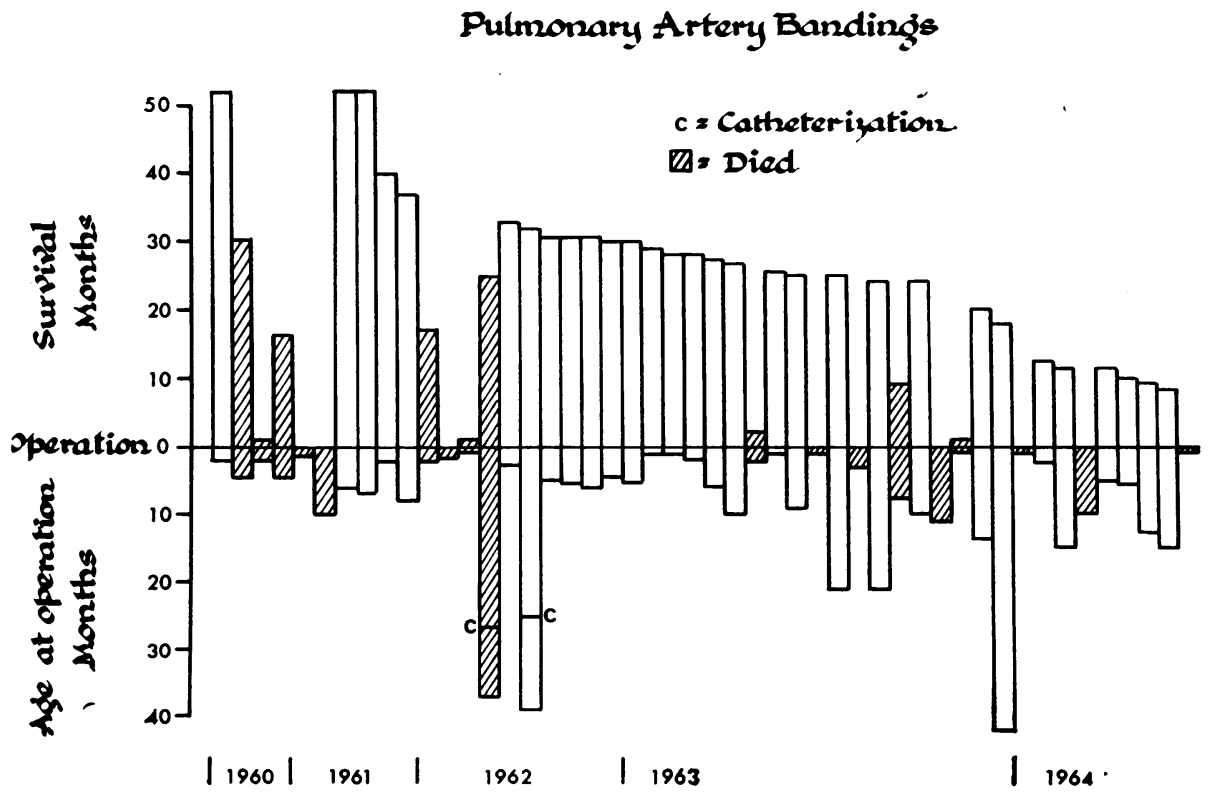

FIG. 1.-Pulmonary artery bandings in $\mathbf{4 8}$ children. The banded cases are shown here in order of operation from 1960 to 1964 . Cardiac catheterization preceded operation by a few days in all cases except two (Cases 14 and 16) where the time of catheterization is indicated by a horizontal line. 
two or three days ( 5 cases). Three of the infants who died of cardiac arrest had experienced an episode of arrest requiring external cardiac massage during cardiac catheterization.

The complexity of the lesions encountered was a further cause of the high mortality: three patients with coincident ventricular septal defect, patent ductus arteriosus, and coarctation were in this group. They weighed from 5 to $8 \mathrm{lb}$. (2267$3628 \mathrm{~g}$.) at the time of operation. The survivor with this combination of anomalies was aged 2 months at catheterization and 10 weeks at operation which included a successful resection of the coarctation. He weighed $9 \mathrm{lb} .10 \mathrm{oz}$. (4635 g.) at the time of operation.

Four late deaths were due to intercurrent infections, one known to be meningitis, one measles. The remaining two infants were thought to be suffering from mild chest infections. In all four cases death was unexpected, and it is possible that these children are less able to combat childhood illnesses than their fellows.

Two children who died late had become deeply cyanosed. In both instances they had suffered from a number of alarming cyanotic attacks. Death occurred from syncope in each case, one 46 months after operation (Case 2), the other 18 months after banding (Case 11). Two further children, also cyanosed, have died in the post-operative period following removal of the band on the pulmonary artery and closure of the septal defect (Cases 12 and 14).

The Post-operative State in the Survivors. Of the 48 children who had their pulmonary artery banded, 29 are alive at present. The post-operative period of follow-up ranges from 15 to 57 months: Fig. 1 presents the follow-up of each patient till July 1965.

Of the 29 children, 22 are well and without cyanosis or significant dyspnœa. They have all grown reasonably well and gained weight. The majority of the children are gaining weight at the lower 10th percentile, but a few children gained weight rapidly immediately after the operation and are continuing to gain weight along the upper tenth percentile (Fig. 2).

All of the 22 children who are of school age are attending normal schools without restrictions, and

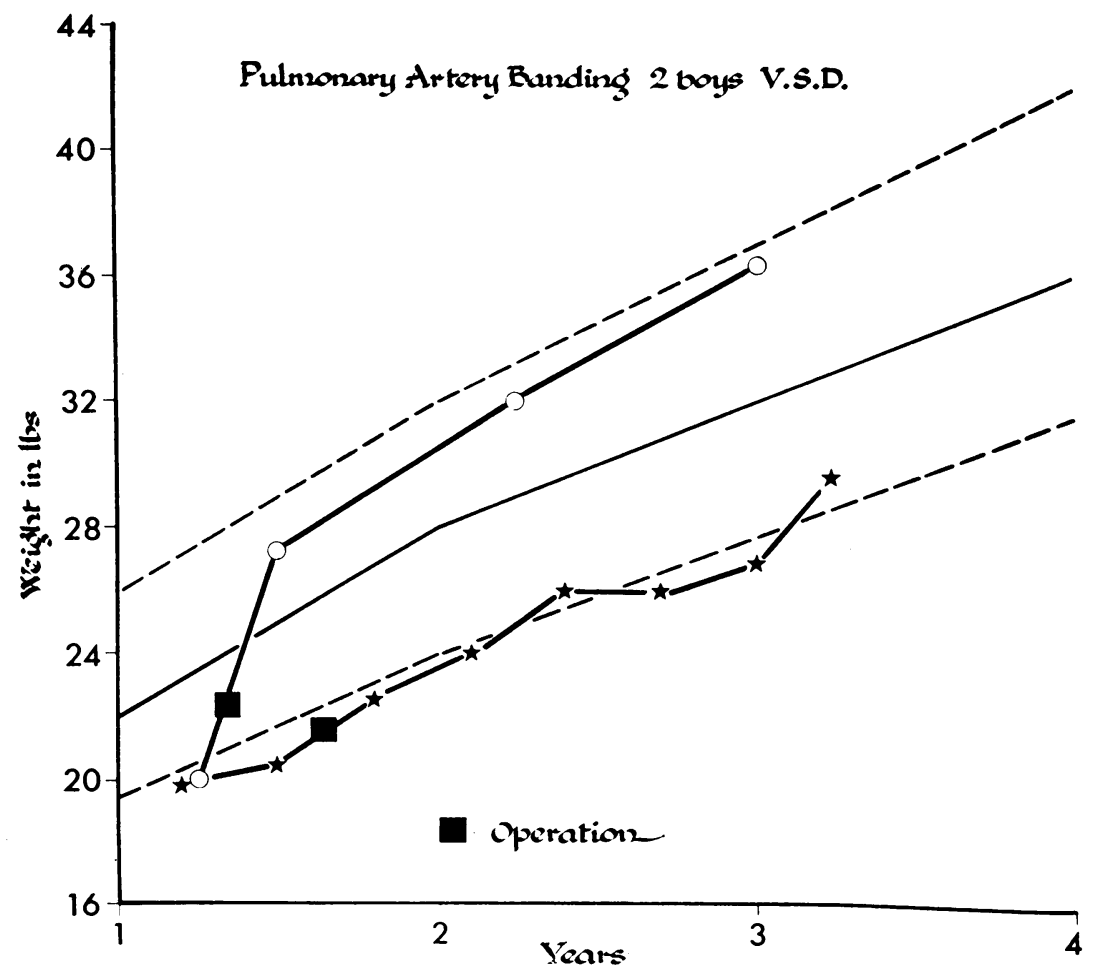

FIG. 2.-Representative weight change after operation. The majority of cases gain weight near the 10th percentile. The continuous line is the mean normal weight gain, the upper interrupted line is the 90 th percentile, the lower interrupted line is the 10th percentile. 
are capable of playing games along with their fellows without discomfort. They all seem to be healthy children and cannot be distinguished by appearance from their sibs (Fig. 3).

None of these 22 children has been reinvestigated by cardiac catheterization, as their clinical progress does not warrant the small risk of a second catheterization, and we believe that corrective surgery should be delayed until they are older. Their conventional chest $x$-ray films and electrocardiograms suggest that the left-to-right shunt is controlled and that the right ventricle is reacting by hypertrophy to the operative obstruction of its outflow.

Nine children in whom the clinical course has given rise to concern have been reinvestigated by cardiac catheterization. In 8 of them intermittent or continuous cyanosis had developed: the ninth (Case 23) had had two syncopal attacks. The results of the investigations are shown in Table II and these children are considered in detail in a subsequent section.

\section{Discussion}

Diagnosis. In the total series of 60 children investigated, only one was completely misdiagnosed.

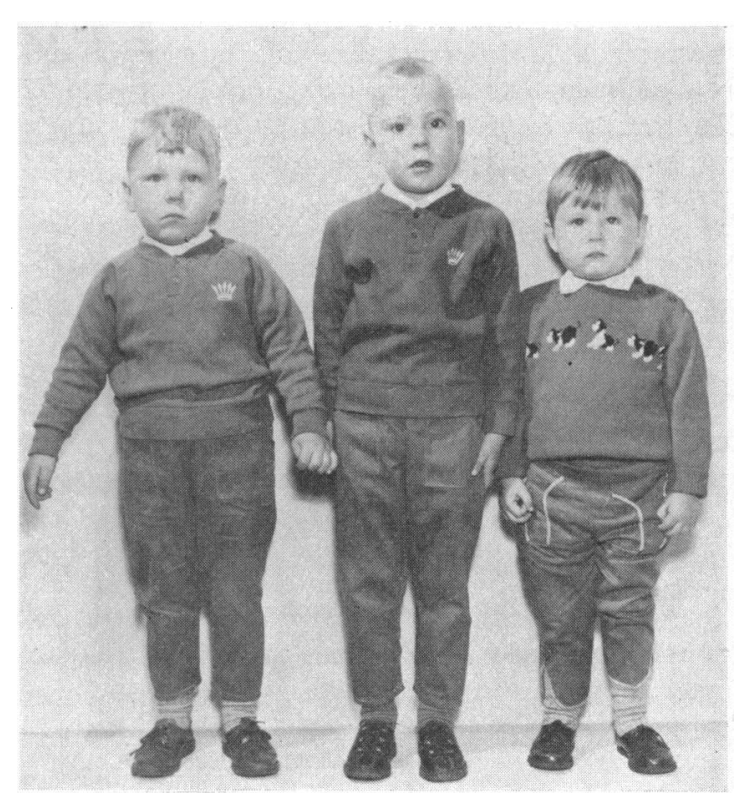

Fig. 3.-Case 1 aged 5 in the centre, $4 \frac{1}{2}$ years after banding, with his two brothers aged 4 and $2 \frac{1}{2}$. He is a fit symptomless child.

TABLE II

DATA ON CASES CATHETERIZED AFTER BANDING

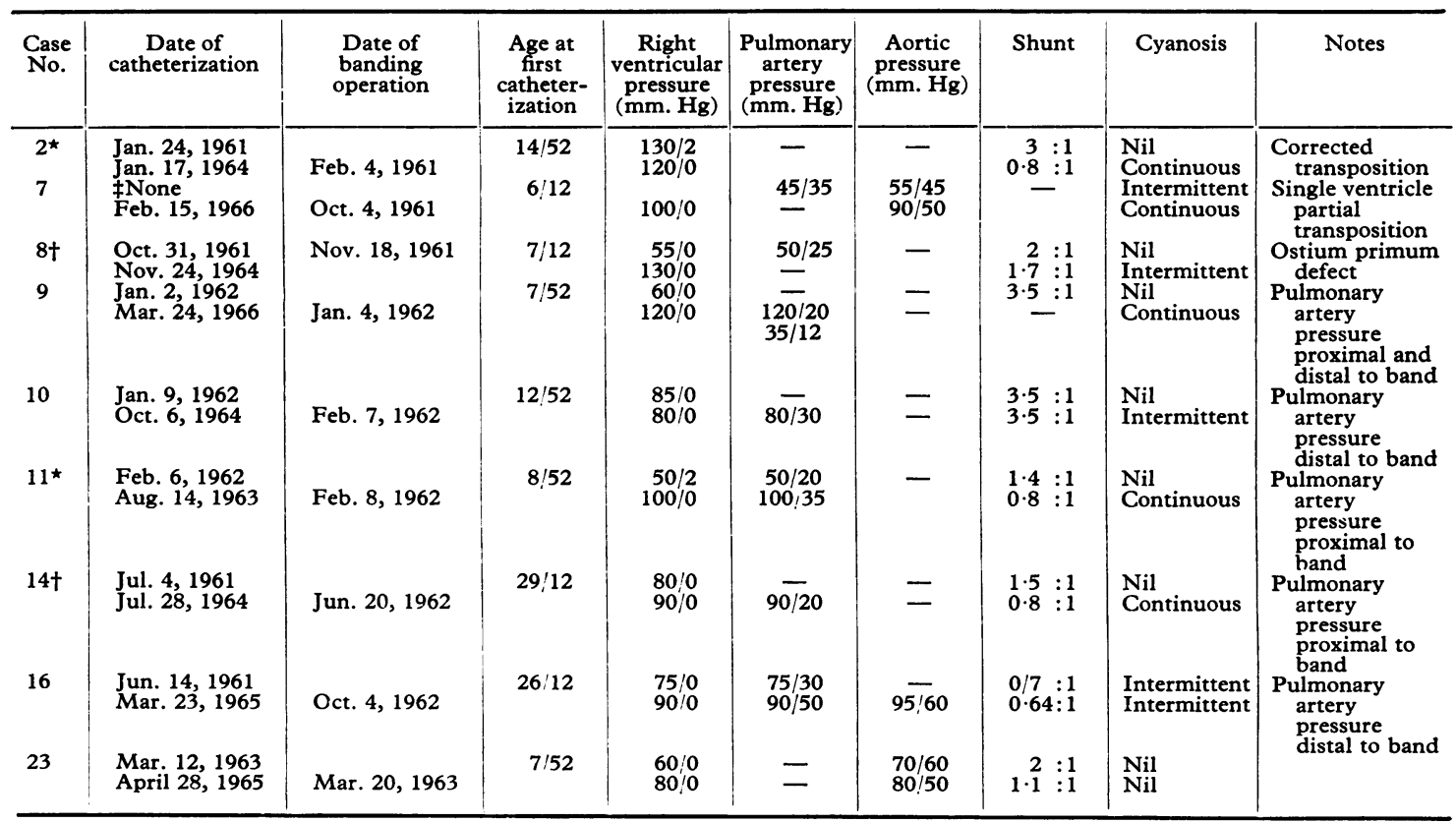

^ Cases 2 and 11 died of syncope while deeply cyanosed.

+ Cases 8 and 14 died after repair of defect and removal of band.

\# In Case 7 a clinical diagnosis of patent ductus arteriosus with septal defect was made. A failure in the diagnostic apparatus had occurred and immediate operation was undertaken to avoid delay. 
Of the 59 other children, the diagnosis which had been made on the catheterization evidence was substantially confirmed at operation or necropsy in 52 . In the other 7 children, the subsequent clinical progress has supported the diagnosis which had previously been made. Case 7 had no pre-operative catheterization.

It has been emphasized that our angiographic technique may not detect a patent ductus if there is another proximal left-to-right shunt. This is because the pulmonary artery, during angiocardiography, will have already been opacified via a leftto-right shunt at atrial or ventricular level. The presence of a patent ductus was correctly diagnosed, however, in 9 of the 16 children in whom it coexisted with a ventricular septal defect. The diagnosis was made by passing the catheter through the ductus in each case. Oximetry provided less certain evidence of a duct, since a considerable left-toright shunt at ventricular level was often found at catheterization to be associated with a left-to-right shunt at ductus level. It seems to us that aortography is not justified in order to establish the presence of a patent ductus in these cases, for the surgeon can readily inspect the area at operation. Most of these children are so small that a femoral artery may have to be used for aortography and it is hoped to preserve the femoral arteries for later open-heart surgery.

A difficulty we have encountered in pre-operative diagnosis is in distinguishing an ostium primum defect from a combined atrial septal defect and ventricular septal defect. In one patient (Case 8), catheterization on two occasions suggested a ventricular septal defect with left-to-right shunt: right ventricular angiocardiography performed at the first investigation, and right ventricular and left atrial at the second, supported the diagnosis. At operation, a large ostium primum defect in the lower part of the atrial septum was found. Presumably the left-to-right shunt of oxygenated blood was passing immediately from the right atrium through the tricuspid valve without mixing with the venous blood of the right atrium. The most useful clue to the correct diagnosis in these cases is left axis deviation on the electrocardiogram. We have had similar difficulty in this diagnosis with adults. If the catheter traverses an atrial septal defect and if angiography and oximetry suggest a ventricular septal defect with left-to-right shunt, we have diagnosed a combined atrial and ventricular septal defect, but we appreciate that some of these patients may have an ostium primum as the sole defect. However, the combination of secundum type atrial septal defect with coexisting ventricular septal defect was diagnosed correctly on the catheter data in one of the four patients who died while awaiting surgery.

The single case with a completely erroneous preoperative diagnosis was an infant, 29 days old, in unremitting heart failure. The atrial samples had all been taken along the lateral border of the right atrium and they had failed to demonstrate the arterial blood entering the atrium from the lungs via anomalous pulmonary veins. Angiocardiography was not available on this occasion. We have since made this diagnosis correctly in two similar infants by angiocardiography.

We believe that good angiocardiograms obtained in two planes on full-sized film are essential to an adequate pre-operative diagnosis in these ill infants.

Operative Mortality. The majority of infants who died as a result of surgery were puny infants with grossly congested lungs. Medical treatment in these babies had failed to relieve their symptoms and many were so weak that they had to be tubefed. The high operative risks in this group appeared well justified in light of the successful results obtained in similar patients who survived and the disastrous course in those in whom operation was delayed.

The Recatheterized Children. The non-cyanosed case. One child (Case 23) was recatheterized as she had twice fainted. In the eight months following this second catheterization she has had no further syncopal attacks (their cause has not been elucidated) and we believe that the catheter data represent the findings in the only uncomplicated case in this series to be reinvestigated. The shunt is controlled by the band, the arterial saturation is normal, and there has been a moderate rise in right ventricular pressure (Table II). The pressure beyond the band was not measured at catheterization, as the catheter would not pass through this narrowed segment which was demonstrated by angiocardiogram (Fig. $4 \mathrm{~A}$ and $\mathrm{B}$ ).

The Cyanotic Cases. Eight banded patients have developed cyanosis nine months to two years after pulmonary artery banding. A similar complication has been mentioned by others reporting their results of this operation. Dammann et al. (1961) found systematic arterial saturations ranging from 73 to 91 per cent in 4 of 11 patients who were investigated after banding. Therkelsen et al. (1959) reported cyanosis in 1 out of 10 who survived operation. Sirak et al. (1959) and Mills et al. (1960) both describe single cases in which cyanosis was the indication for the successful reconstitution of the pulmonary artery with closure of the defect. 


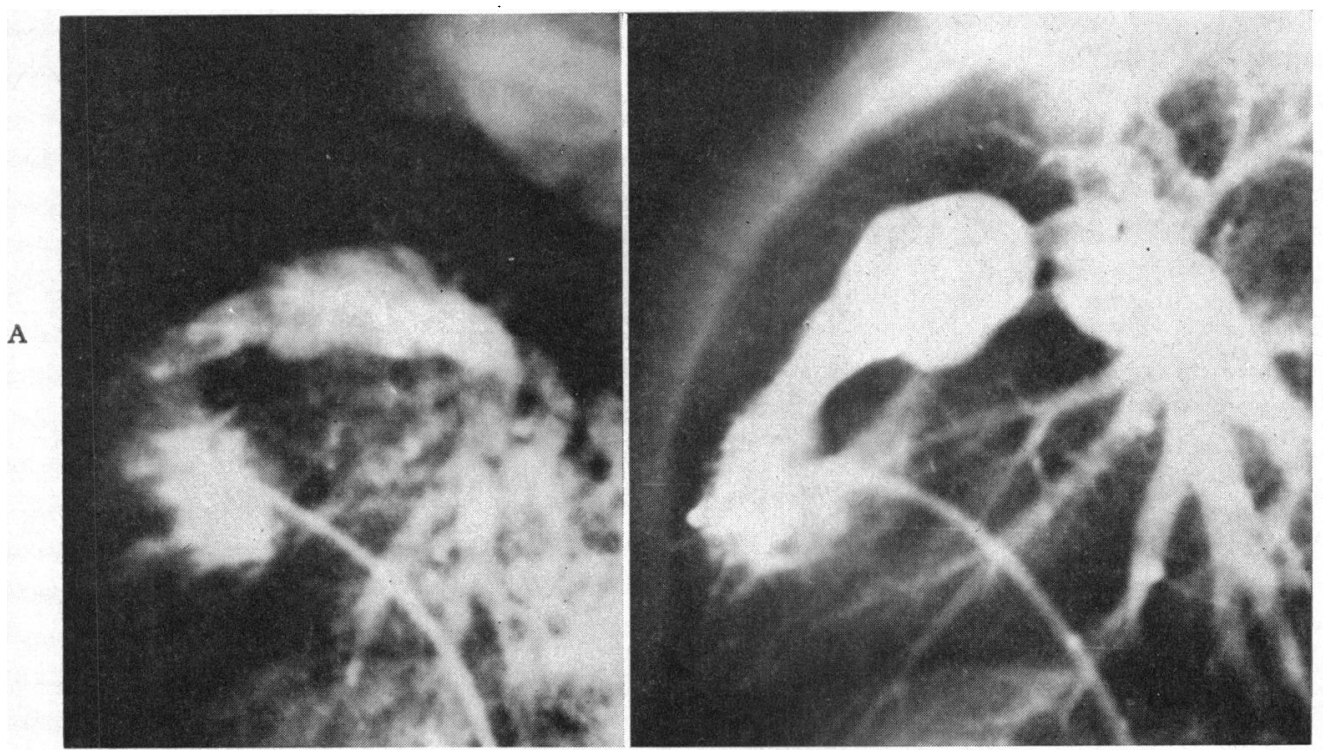

Fig. 4.-Angiocardiograms from Case 23. (A) Lateral projection before banding, at the age of 8 weeks. Right ventricular injection showing normal outflow tract and pulmonary artery. B. Lateral projection 2 years and 1 month after pulmonary artery banding. Right ventricular injection shows marked constriction due to banding of the pulmonary artery. Moderate pre- and post-stenotic dilatation.

Albert et al. (1961) state that their patients showed features of a mild Fallot after three to five years.

Our eight cyanosed cases can be divided into two groups on the catheterization data. In 6 (Cases 2,7 , $8,9,11$, and 14) the band appears to have resulted in a stenosis of the pulmonary artery which has become inadequate to pass enough blood to the lungs as the child's size increased. In all these children the initial post-operative course was good: evidence of heart failure receded and they gained weight, requiring neither digoxin nor diuretics. Cyanosis came on after nine months (Case 11) to four years (Case 8). The stenosis in the artery was traversed at the catheterization in only one of these children (Case 9), but a section through the banded area shows clearly the thinner wall of the artery distal to the band (Fig. 5, Case 2), and the angiographic appearances also suggest a great reduction in previously high pulmonary blood flow (Fig. 6 $A, B$, and C). The syncopal deaths in two of these children have already been mentioned (Cases 2 and 11) and followed a series of cyanotic attacks closely resembling those seen in Fallot's tetralogy.

In the other two cyanosed patients (Cases 10 and 16), the catheter readily passed the operative pulmonary artery constriction and no gradient was detected. Case 10 did not appear to differ from the majority of the other infants submitted to operation: there was evidence of a large left-to-right shunt be-

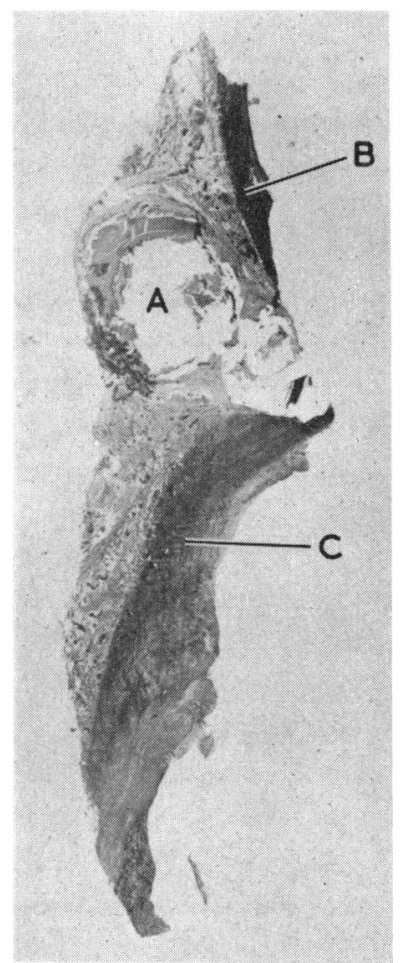

Fig. 5.-Section through banded pulmonary artery (Case 2).

(A) Silk thread heavily impregnated with calcium salts.

(B) Elastic layer distal to band. (C) Elastic layer proximal to band, more than twice as thick as $B$. 
fore banding and this does not appear to have been affected by the band, though at operation adequate reduction in the pulmonary arterial pressure and pulsation was observed. The child is now thin and dyspnœic, and needs digoxin. A similar but uncyanosed case is described by Therkelsen et al. (1959). The remaining patient (Case 16) is unusual in that there appeared to be an established Eisenmenger reaction present at her initial catheterization and operation. Her clinical condition has been unchanged by surgery; she continues to be a puny and dyspnœic child. Whereas Case 10 is only cyanosed on considerable exertion and is not clubbed, Case 16 is free of cyanosis only when asleep and had doubtful clubbing at the time of the initial banding.

Results in Early Eisenmenger Reaction. In most infants in this series in whom the pulmonary and systemic arterial pressures were balanced, the dynamic nature of this balance was apparent from the large left-to-right shunt and the dramatic rise in systemic pressure, noted during operation, that accompanied the surgical control of the pulmonary artery blood flow and left-to-right shunt.
In 3 infants there appeared to be good clinical and catheterization data to suggest that the balance in pressure was due to increased pulmonary vascular resistance (Cases 14, 16, and 39). In 2 patients (Cases 14 and 39) pulmonary artery banding successfully reversed a downward clinical course; the children put on weight and lost all evidence of heart failure. In Case 39, this satisfactory state continued two years after operation. Similarly successful control of Eisenmenger reaction has been reported by Dammann et al. (1961) and by Goldblatt et al. (1965).

The distinction between this group, with high peripheral resistance, and the group in which the hypertension in the pulmonary circuit is due to a large shunt, is, we believe, a real one. It is, however, difficult to define the position exactly in some of these small babies. In many of them the ventricular septal defects are large, and bi-directional shunting occurs. In many cases with ventricular septal defect and patent ductus arteriosus the shunt is left to right at ventricular level but right to left at the duct. Calculations of peripheral vascular resistance in such infants do not seem to us to have critical value, and, indeed, the calculations of the

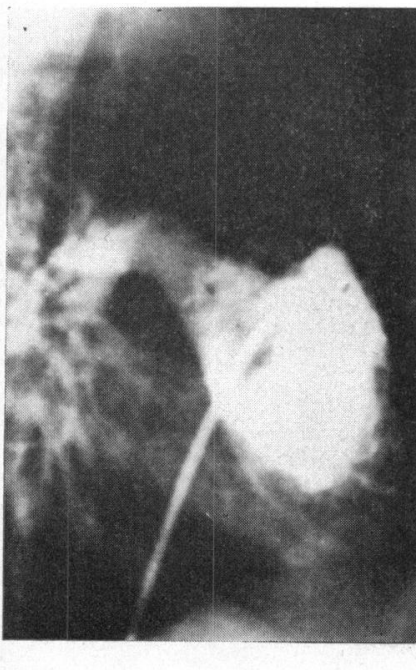

A

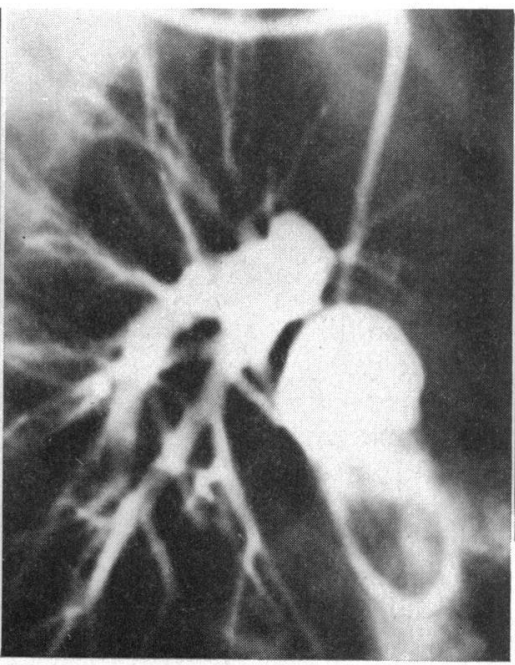

B

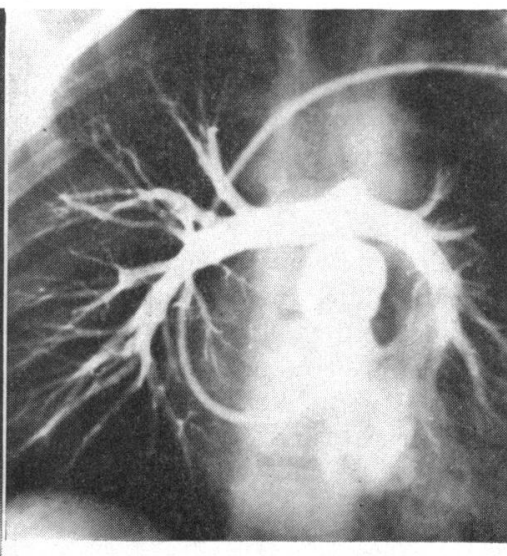

C

FIG. 6.-Angiocardiograms from Case 2. At the initial investigation a corrected transposition with ventricular septal defect was diagnosed. The infant was 4 months old. (A) Lateral projection before operation. Left ventricular injection showing the posterior origin of the pulmonary artery. There is no obstruction to the outflow of the ventricle. (Both ventricles were placed anteriorly in the same coronal plane.) (B) Lateral projection 3 years 10 months later. Left ventricular injection showing marked constriction due to banding with moderate dilatation of the pulmonary artery both proximal and distal to the band. (C) Antero-posterior projection at the same time as (B). The same injection showing constriction of the pulmonary artery. The peripheral pulmonary vessels are probably smaller than normal and are reduced when compared with the plethora that was present before banding. 
shunts in Table II can only be regarded as being an indifferent index of the hæmodynamic state.

Value of the Operation. Our experience confirms that of other workers that pulmonary artery banding is a life-saving operation for infants in heart failure as a result of large left-to-right shunts. It may also be of great value with developing Eisenmenger reaction. There is good evidence from serial biopsy specimens that the operation is followed by regression of the hypertensive changes in the lung vasculature (Dammann et al., 1961). The operation is a makeshift in that a repair has to be undertaken at a later date, but primary closure of large ventricular septal defects in small infants is not as yet possible with an acceptable mortality (Kirklin, McGoon, and DuShane, 1960; Kirklin and DuShane, 1961; Ochsner et al., 1962).

The main technical criticism of the operation is the difficulty in controlling the degree of the banding. Pressure measurement is the most readily available index, but is clearly not infallible as is apparent from the subsequent findings in Cases 10 and 16 where reinvestigation showed no gradient at the site of the band.

\section{SUMMARY}

A series of 60 infants with septal defects transmitting a left-to-right shunt is reported. In nearly all the septal defect was ventricular. Most of these infants presented with recurrent heart failure.

Pulmonary artery banding was done on 48 of the series. Follow-up has ranged from 15 months to 6 years. The majority of the 29 survivors are symptomless and growing normally. The commonest late complication of the operation (8 patients) is the appearance of cyanosis. Investigation has shown that in some cases this is due to the lumen of the artery becoming inadequate for the growing child, in others to the persistence of Eisenmenger's reaction despite the band.

We are indebted to Dr. A. J. N. Warrack for the pulmonary artery section of Case 2 and to the Department of Medical Photography and Illustration, Sheffield United Hospitals, for the illustrations.

\section{REFERENCES}

Albert, H. M., Atik, M., and Fowler, R. (1958). Production and release of pulmonary stenosis in dogs. Surgery, 44, 904.

-, Fowler, R. L., Craighead, C. C., Glass, B. A., and Atik, M. (1961). Pulmonary artery banding: a treatment for infants with intractable cardiac failure due to interventricular septal defects. Circulation, 23, 16.

Boesen, I., and Vendel, S. (1955). Post-mortem diagnosis in 1137 infants under the age of four years with congenital heart disease. Acta padiat. (Uppsala), 44, 392.
Craig, T. V., and Sirak, H. D. (1963). Pulmonary artery banding. An analysis of 38 cases. F. thorac. cardiovasc. Surg., 45, 599.

Dammann, J. F., MacEachen, J. A., Thompson, W. M., Jr., Smith, R., and Muller, W. H., Jr. (1961). The regression of pulmonary vascular disease after the creation of pulmonary stenosis. F. thorac. cardiovasc. Surg., 42, 722.

Fowler, R. L., Albert, H. M., Novick, R., Puyan, F. A., and Craighead, C. C. (1958). Response of infants with large ventricular septal defects to banding of the pulmonary artery. (Abstract.) Circulation, 18, 720.

Gerbode, F., and Selzer, A. (1948). Experimental cardiac hypertrophy. The acute effect of pulmonic and aortic stenosis. Surgery, 24, 505.

Goldblatt, A., Bernhard, W. F., Nadas, A. S., and Gross, R. E. (1965). Pulmonary artery banding. Indications and results in infants and children. Circulation, 32, 172.

Grainger, R. G., Taylor, D. G., and Verel, D. (1966). Cardiac catheterization and selective angiocardiography in congenital heart disease presenting in the neonate. Clin. radiol., 17, 12.

Holman, E., and Beck, C. S. (1926). The physiological response of the circulatory system to experimental alterations. III. The effect of aortic and pulmonary stenoses. F. clin. Invest., 3, 283.

Hufnagel, C. A., Roe, B. B., and Barger, A. C. (1951). A technique for producing pulmonary artery stenosis. Surgery, 29, 77.

Kaplan, S., Daoud, G. I., Benzing, G., III, Devine, F. J., Glass, I. H., and McGuire, J. (1963). Natural history of ventricular septal defect. Amer. F. Dis. Child., 105, 581.

Kirklin, J. W., and DuShane, J. W. (1961). Repair of ventricular septal defect in infancy. Pediatrics, 27, 961.

-, McGoon, D. C., and DuShane, J. W. (1960). Surgical treatment of ventricular septal defect. F. thorac. cardiovasc. surg., 40, 763.

Lynfield, J., Gasul, B. M., Arcilla, R., and Luan, K. L. (1961). The natural history of ventricular septal defect in infancy. Amer. F. Med., 30, 357.

Marquis, R. M. (1950). Ventricular septal defect in early childhood. Brit. Heart f., 12, 265.

Mills, H., Kay, J. H., Magidson, O., Anderson, R. M., and Schiff, A. (1960). Correction of congenital ventricular septal defect in a patient with previous surgically produced pulmonary artery stenosis. Amer. F. Cardiol., 6, 976.

Morgan, B. C., Griffiths, S. P., and Blumenthal, S. (1960). Ventricular septal defect. I. Congestive heart failure in infancy. Pediatrics, 25, 54.

Morrow, A. G., and Braunwald, N. S. (1961). The surgical treatment of ventricular septal defect in infancy. Circulation, 24, 34.

Muller, W. H., and Dammann, J. F., Jr. (1952). The treatment of certain congenital malformations of the heart by the creation of pulmonary stenosis to reduce pulmonary hypertension and excessive pulmonary blood flow. Surg. Gynec. Obstet,, 95, 213.

Ochsner, J. L., Cooley, D. A., McNamara, D. G., and Kline, A. (1962). Surgical treatment of cardiovascular anomalies in 300 infants younger than one year of age. F. thorac. cardiovasc. Surg., 43, 182.

Reid, M. R. (1924). Partial occlusion of the pulmonary aorta and inferior vena cava with the metallic band. Observations on changes in the vessel wall and in the heart. f. $\exp$. Med., 40, 289. 
Sirak, H. D., Hosier, D. M., and Clatworthy, H. W. (1959). Defects of the interventricular septum in infancy: A two-stage approach to their surgical correction. New Engl. F. Med., 260, 147.

Smith, R. T., and MacEachen, J. A. (1960). Evaluation of the Dammann-Muller procedure for large left-to-right shunts in infancy. Surg. Forum, 11, 254.

Therkelsen, F., Gammelgaard, P. A., and Boesen, I. (1959). Ventricular septal defects in infants treated with various modifications of the Dammann-Muller operation. Acta chir. scand., Suppl. 245, 249.

Thompson, W. M., Jr., Muller, W. H., Jr., and Dammann, J. F., Jr. (1958). Analysis of clinical results from the surgical creation of pulmonary stenosis in thirty-five patients with large intracardiac communications. (Abstract). Circulation, 18, 789.

Willman, V. L., Cooper, T., Mudd, J. G., and Hanlon, C. R. (1962). Treatment of ventricular septal defect by constriction of pulmonary artery. Arch. Surg., 85, 745. 